\title{
KEBIJAKAN STRUKTUR MODAL DAN EFEK WAKTU PASAR
}

\author{
Winston Pontoh \\ (Email : winston_pontoh@yahoo.com)
}

\begin{abstract}
The capital structure policy of each entities often related with two main theories which are trade off and pecking order. But, there is another factor that could affecting the capital structure, which is market timing. The objective of this study is prove whether the capital structure of each entities are affected by these two main theories or market timing. Conducting regression analysis, this study found that, the capital structure of each entities in Indonesia most dominated by market timing, although as general, seems these entities following trade off model.
\end{abstract}

Keywords : capital structure, trade off, pecking order, market timing

\section{Pendahuluan}

Permasalahan atas penetapan struktur modal hingga pada saat ini masih terkait erat dengan teori trade off dan teori pecking order (Elliott, Kant, dan Warr, 2008), akan tetapi waktu pasar (market timing) juga merupakan salah satu faktor dalam penetapan struktur modal (Alti, 2006). Penentuan atas struktur modal selalu akan dikaitkan dengan pertimbangan dari biaya modal tersebut (Elliott, Kant, dan Warr, 2008). Oleh sebab itu, pihak internal dari sebuah entitas bisnis harus mempertimbangkan biaya modal secara seksama dalam rangka penentuan sumber pembiayaan atas investasinya, yaitu apakah akan menggunakan modal sendiri atau modal utang.

Menurut pendapat Myers (2001), dalam implikasi trade off theory, entitas-entitas bisnis akan mencari tingkat utang yang akan memberikan mereka manfaat pajak untuk setiap ketambahan utang selain biaya-biaya yang mungkin muncul akibat adanya kesenjangan keuangan, sehingga teori ini memprediksikan bahwa, terjadinya utang berskala menengah dilakukan oleh entitas-entitas bisnis pembayar pajak. Sedangkan dalam implikasi pecking order theory, entitas bisnis akan melakukan pinjaman, pada saat dana tunai internal tidak mencukupi untuk membiayai pengeluaran modal.

Penelitian ini dilakukan dengan tujuan untuk membuktikan apakah penentuan struktur modal sebuah entitas bisnis didasarkan pada kedua teori utama dalam struktur modal (trade off dan pecking order) atau didasarkan pada waktu pasar (market timing) yang dapat memungkinkan sebuah entitas bisnis untuk memperoleh pendanaan eksternal dalam rangka membiayai investasinya.

\section{Tinjauan Pustaka}

Menurut Titman dan Wessels (1988), sebuah entitas bisnis yang memiliki profitabilitas yang tinggi sering menggunakan saldo laba mereka untuk menutupi utang, sehingga, entitas bisnis tersebut terlihat kurang dalam menggunakan utang. Hovakimian, Opler, dan Titman (2001) menyatakan bahwa, semakin profit sebuah entitas bisnis, maka secara umum, akan memiliki rasio utang yang rendah. Selain itu, semakin profit sebuah entitas bisnis, kecenderungan entitas bisnis tersebut untuk memperoleh utang adalah semakin tinggi dibandingkan dengan menerbitkan ekuitas, dan entitas bisnis tersebut cenderung untuk melakukan pembelian kembali sahamnya dibandingkan dengan menggunakan utang.

Hovakimian, Opler, dan Titman (2001) menemukan bahwa, sebuah entitas bisnis yang memiliki harga pasar saham yang tinggi (dibandingkan dengan harga pasar sebelumnya, nilai buku atau laba) akan cenderung untuk menerbitkan saham dibandingkan dengan utang dan membeli obligasinya dibandingkan dengan pembelian kembali sahamnya. Pendapat ini 
didukung oleh Baker dan Wurgler (2002) berpendapat bahwa, asumsi hipotesis dari pemilihan waktu pasar adalah berasal dari perilaku entitas bisnis yang umum, yaitu menerbitkan saham pada saat memiliki harga pasar yang tinggi, dan melakukan pembelian kembali saham yang diterbitkan pada saat memiliki harga pasar yang cukup rendah.

Menurut Brendea (2012), dalam konteks pemilihan waktu pasar (market timing), secara spesifik, beberapa dasar pertimbangan sebuah entitas bisnis dalam penentuan struktur modal yang akan digunakan sebagai sumber pendanaan adalah profitabilitas, ukuran perusahaan, dan aset tetap. Brendea (2012) menyatakan bahwa, dalam teori pemilihan waktu pasar, entitas bisnis cenderung untuk menerbitkan saham pada saat nilai pasar atau harga saham berada pada nilai yang tinggi, dibandingkan dengan nilai buku atau nilai pasar sebelumnya, atau membeli kembali sahamnya pada saat nilai pasar atau harga saham berada pada nilai yang rendah. Perilaku pendanaan mengimplikasikan bahwa sebuah entitas bisnis akan cenderung memilih pendanaan ekuitas ketika biaya modalnya rendah. Sebaliknya, entitas bisnis akan memilih penggunaan utang ketika biaya modal tinggi.

Clayton dan Reisel (2013) menyatakan bahwa, rasio utang yang optimal adalah rasio utang yang terbentuk ketika batas manfaat dari setiap tambahan utang adalah sama dengan batasan biayanya ditambah dengan arus kas masa depan yang diharapkan dan peluang investasi yang potensial. Pada saat rasio utang berada pada posisi optimal, entitas bisnis kemungkinan akan mengubah tingkat utang yang optimal tersebut karena tingkat utang yang ada dapat mengurangi nilai entitas jika realisasi arus kas kurang dari yang diharapkan.

\section{Hipotesis dan Model}

Menurut Myers (2001), dalam sudut pandang pecking order, sebuah rasio utang dari entitas bisnis akan menjadi rendah atau negatif ketika profitabilitas adalah tinggi, sehingga semakin tinggi profitabilitas, maka rasio utang akan semakin rendah. Sedangkan dalam sudut pandang trade off, entitas bisnis yang memiliki profitabilitas yang tinggi, akan semakin memerlukan utang dalam jumlah yang besar, guna memperoleh manfaat pajak. Hasil penelitian ini didukung oleh Jensen, Solberg, dan Zorn (1992), Rajan dan Zingales (1995), Berger, Ofek, dan Yermack (1997), Crutchley, Jensen, Jahera, dan Raymond (1999), Booth, Aivazian, Kunt, dan Maksimovic (2001), Hovakimian, Opler, dan Titman (2001), Fama dan French (2002), Frank dan Goyal (2003), Chen (2004), dan Cheng dan Shiu (2007).

\section{$\mathrm{Ha}_{1}$ : Profitabilitas memiliki pengaruh signifikan terhadap rasio utang.}

Asquith dan Mullins (1986) menjelaskan bahwa, sebuah entitas bisnis akan cenderung untuk menerbitkan saham apabila terjadi peningkatan dalam harga pasar saham, yang mengimplikasikan entitas bisnis tersebut akan berusaha untuk mengurangi rasio utang mereka. Hasil penelitian ini didukung oleh Hovakimian, Hovakimian, dan Tehranian (2004), Cheng dan Shiu (2007), Cai dan Zhang (2011), Frank dan Goyal (2004) dan Kayhan dan Titman (2007).

\section{$\mathrm{Ha}_{2}$ : Harga pasar saham memiliki pengaruh signifikan terhadap rasio utang.}

Rajan dan Zingales (1995) menemukan bahwa, terdapat ukuran entitas bisnis akan memiliki pengaruh positif signifikan terhadap rasio utang, yang disebabkan karena entitas bisnis yang berukuran lebih besar pada dasarnya terdiversifikasi dengan lebih baik dan memiliki kemungkinan yang kecil untuk mengalami kesulitan keuangan. Hasil penelitian ini didukung oleh Graham (1996), Berger, Ofek, dan Yermack (1997), Udomsirikul, Jumreornvong, dan Jiraporn (2011), Amore, Minichilli, dan Corbetta (2011), Hovakimian, Opler, dan Titman (2001), Booth, Aivazian, Kunt, dan Maksimovic (2001), Frank dan Goyal (2003), Cheng dan Shiu (2007), Elliott, Kant, dan Warr (2008).

$\mathrm{Ha}_{3}$ : Ukuran memiliki pengaruh signifikan terhadap rasio utang. 
Berdasarkan rumusan hipotesis, maka model persamaan dalam penelitian ini dapat dirumuskan sebagai berikut :

$\mathrm{DER}=\alpha+\beta \mathrm{ROE}+\beta$ Price $+\beta$ Size

\section{Metode Penelitian}

\subsection{Data}

Data dalam penelitian ini mengambil sampel 165 entitas bisnis yang terdaftar dalam Bursa Efek Indonesia pada periode tahun 2009 sampai dengan tahun 2012, dengan kriteria, memiliki nilai positif atas total ekuitas dan tidak mengalami rugi bersih. Data observasi dalam penelitian ini secara keseluruhan adalah berjumlah 660 data observasi.

\subsection{Variabel dan Pengukuran Variabel}

Penelitian ini menggunakan 2 (dua) jenis variabel dependen yaitu rasio total utang atas total ekuitas (selanjutnya disingkat dengan DER). Sedangkan variabel independen yang digunakan dalam penelitian ini adalah rasio laba bersih atas total ekuitas (disingkat dengan ROE), harga pasar saham penutupan pada akhir tahun (disingkat dengan Price), dan ukuran perusahaan yang diukur dengan logaritma natural total aset (disingkat dengan Size). Variabel yang digunakan dalam penelitian ini, dinormalisasi dengan menggunakan logaritma natural.

\subsection{Metode Analisis}

Dalam penelitian ini, metode analisis yang akan digunakan untuk pengujian hipotesis adalah menggunakan uji regresi berganda yang digunakan berdasarkan data panel. Dalam penerapan analisis regresi, untuk tujuan interpretasi hasil analisis, maka variabel DER dan Size akan dikontrol berdasarkan nilai tengah (median) masing-masing periode. Entitas-entitas bisnis yang memiliki rasio utang (DER) dibawah nilai tengah (selanjutnya disebut <med), akan dianalogikan sebagai entitas yang memiliki rasio utang yang rendah dan begitu pula sebaliknya. Sedangkan entitas bisnis yang memiliki ukuran (Size) dibawah nilai tengah, akan dianalogikan sebagai entitas yang memiliki ukuran yang kecil dan begitu pula sebaliknya. Khusus untuk variabel ukuran (Size), kode dummy akan dikontrol berdasarkan nilai tengah.

\section{Hasil Analisis dan Pembahasan}

\subsection{Hasil Analisis}

Hasil analisis regresi berganda secara umum menunjukkan bahwa, profitabilitas, harga saham dan ukuran entitas secara signifikan mempengaruhi rasio utang dari sebuah entitas bisnis. Persamaan regresi dari hasil analisis adalah :

\section{DER = -0.407 + 0.125ROE - 0.160Price + 0.112Size}

Pada tahun 2009 (lihat Tabel 1), hasil analisis menunjukkan bahwa, secara umum, harga pasar saham memiliki pengaruh secara signifikan terhadap rasio utang bagi entitas-entitas bisnis yang memiliki rasio utang yang rendah. Apabila dilakukan kontrol terhadap ukuran (Size) entitas, maka bagi entitas-entitas bisnis dengan rasio utang yang rendah, rasio utang akan dipengaruhi oleh ukuran entitas bisnis. Sedangkan bagi entitas-entitas bisnis yang memiliki rasio utang yang tinggi, rasio laba bersih atas total ekuitas memiliki pengaruh signifikan terhadap rasio utang.

Pada tahun 2010 (lihat Tabel 2), hasil analisis menunjukkan bahwa, secara umum, rasio utang dari entitas-entitas bisnis yang memiliki rasio utang yang rendah akan dipengaruhi secara signifikan oleh harga pasar saham dan ukuran entitas. Hasil yang berbeda ditunjukkan pada saat dilakukan kontrol atas variabel ukuran, dimana variabel ukuran tidak memiliki pengaruh signifikan terhadap rasio utang. Sebaliknya, bagi entitas-entitas bisnis dengan rasio utang yang tinggi, semua variabel independen tidak memiliki pengaruh signifikan. 
Pada tahun 2011 (lihat Tabel 3), hasil analisis menunjukkan bahwa, secara umum, rasio utang dari entitas-entitas bisnis yang memiliki rasio utang yang rendah akan dipengaruhi secara signifikan oleh harga pasar saham dan ukuran entitas. Hasil yang sama juga ditunjukkan apabila dilakukan kontrol terhadap variabel ukuran. Sedangkan pada tahun 2012 (lihat Tabel 4), hasil analisis menunjukkan bahwa, secara umum, rasio utang dari entitasentitas bisnis dengan rasio utang yang rendah dipengaruhi secara signifikan oleh harga pasar saham dan ukuran entitas.

Tabel 1. Panel A : Analisis Regresi Periode 2009 dengan perbandingan periode 2009-2012

\begin{tabular}{|c|c|c|c|c|c|c|c|}
\hline \multirow{2}{*}{ Variabel Independen } & \multicolumn{7}{|c|}{ Variabel Dependen } \\
\hline & DER $\left(\mathrm{N}_{2009-2012}: 660\right)$ & \multicolumn{3}{|c|}{$\mathrm{DER}_{<\text {med }}\left(\mathrm{N}_{2009}: 82\right)$} & \multicolumn{3}{|c|}{$\mathrm{DER}_{>\text {med }}\left(\mathrm{N}_{2009}: 83\right)$} \\
\hline Konstan & -0.407 & -1.208 & -0.179 & 0.141 & 1.597 & 1.229 & 1.133 \\
\hline ROE & $0.125 *$ & 0.087 & 0.092 & 0.092 & $0.148 *$ & $0.146^{*}$ & $0.146^{*}$ \\
\hline Price & $-0.160 *$ & $-0.103 *$ & -0.095 & -0.095 & -0.028 & -0.034 & -0.034 \\
\hline Size & $0.112 *$ & 0.088 & & & -0.032 & & \\
\hline $\operatorname{Size}_{\text {control }}(>\operatorname{med}=1)$ & & & $0.320 *$ & & & -0.096 & \\
\hline $\operatorname{Size}_{\text {control }}(<\operatorname{med}=1)$ & & & & $-0.320 *$ & & & 0.096 \\
\hline
\end{tabular}

*signifikan pada tingkat $5 \%$

Tabel 2. Panel B : Analisis Regresi Periode 2010 dengan perbandingan periode 2009-2012

\begin{tabular}{|c|c|c|c|c|c|c|c|}
\hline \multirow{2}{*}{ Variabel Independen } & \multicolumn{7}{|c|}{ Variabel Dependen } \\
\hline & $\operatorname{DER}\left(\mathrm{N}_{2009-2012}: 660\right)$ & \multicolumn{3}{|c|}{$\mathrm{DER}_{<\text {med }}\left(\mathrm{N}_{2010}: 82\right)$} & \multicolumn{3}{|c|}{$\operatorname{DER}_{>\text {med }}\left(\mathrm{N}_{2010}: 83\right)$} \\
\hline Konstan & -0.407 & -0.910 & 0.028 & 0.272 & 1.011 & 0.354 & 0.312 \\
\hline ROE & $0.125 *$ & 0.108 & 0.097 & 0.097 & -0.084 & -0.090 & -0.090 \\
\hline Price & $-0.160 *$ & $-0.143^{*}$ & $-0.119 *$ & $-0.119 *$ & 0.033 & 0.002 & 0.002 \\
\hline Size & $0.112^{*}$ & $0.090 *$ & & & -0.061 & & \\
\hline $\operatorname{Size}_{\text {control }}(>\operatorname{med}=1)$ & & & 0.243 & & & -0.041 & \\
\hline $\operatorname{Size}_{\text {control }}(<\operatorname{med}=1)$ & & & & -0.243 & & & 0.041 \\
\hline
\end{tabular}

*signifikan pada tingkat $5 \%$

Tabel 3. Panel C : Analisis Regresi Periode 2011 dengan perbandingan periode 2009-2012

\begin{tabular}{|c|c|c|c|c|c|c|c|}
\hline \multirow{2}{*}{ Variabel Independen } & \multicolumn{7}{|c|}{ Variabel Dependen } \\
\hline & $\operatorname{DER}\left(\mathrm{N}_{2009-2012}: 660\right)$ & \multicolumn{3}{|c|}{$\mathrm{DER}_{<\text {med }}\left(\mathrm{N}_{2011}: 82\right)$} & \multicolumn{3}{|c|}{$\mathrm{DER}_{>\text {med }}\left(\mathrm{N}_{2011}: 83\right)$} \\
\hline Konstan & -0.407 & -0.963 & 0.002 & 0.252 & 0.350 & -0.066 & -0.125 \\
\hline ROE & $0.125 *$ & 0.102 & 0.094 & 0.094 & -0.120 & -0.120 & -0.120 \\
\hline Price & $-0.160 *$ & $-0.131 *$ & $-0.110^{*}$ & $-0.110^{*}$ & 0.062 & 0.047 & 0.047 \\
\hline Size & $0.112 *$ & $0.088 *$ & & & -0.038 & & \\
\hline $\operatorname{Size}_{\text {control }}(>\operatorname{med}=1)$ & & & $0.250 *$ & & & -0.059 & \\
\hline $\operatorname{Size}_{\text {control }}(<\operatorname{med}=1)$ & & & & $-0.250 *$ & & & 0.059 \\
\hline
\end{tabular}

*signifikan pada tingkat $5 \%$

Tabel 4. Panel D : Analisis Regresi Periode 2012 dengan perbandingan periode 2009-2012

\begin{tabular}{|c|c|c|c|c|c|c|c|}
\hline \multirow{2}{*}{ Variabel Independen } & \multicolumn{7}{|c|}{ Variabel Dependen } \\
\hline & $\operatorname{DER}\left(\mathrm{N}_{2009-2012}: 660\right)$ & \multicolumn{3}{|c|}{$\mathrm{DER}_{<\text {med }}\left(\mathrm{N}_{2012}: 82\right)$} & \multicolumn{3}{|c|}{$\mathrm{DER}_{>\text {med }}\left(\mathrm{N}_{2012}: 83\right)$} \\
\hline Konstan & -0.407 & -1.236 & -0.349 & -0.152 & 0.542 & 0.444 & 0.532 \\
\hline $\mathrm{ROE}$ & $0.125^{*}$ & 0.030 & 0.030 & 0.030 & -0.005 & 0.009 & 0.009 \\
\hline Price & $-0.160 *$ & $-0.092 *$ & -0.072 & -0.072 & 0.019 & -0.003 & -0.003 \\
\hline Size & $0.112 *$ & $0.079 *$ & & & -0.016 & & \\
\hline $\operatorname{Size}_{\text {control }}(>\operatorname{med}=1)$ & & & 0.197 & & & 0.087 & \\
\hline $\operatorname{Size}_{\text {control }}(<\operatorname{med}=1)$ & & & & -0.197 & & & -0.087 \\
\hline
\end{tabular}

\subsection{Pembahasan}

Berdasarkan hasil analisis, secara umum, dalam periode 2009 sampai dengan 2012, hasil penelitian ini mendukung hasil-hasil penelitian dari Jensen, Solberg, dan Zorn (1992), Rajan dan Zingales (1995), Berger, Ofek, dan Yermack (1997), Crutchley, Jensen, Jahera, dan 
Raymond (1999), Booth, Aivazian, Kunt, dan Maksimovic (2001), Hovakimian, Opler, dan Titman (2001), Fama dan French (2002), Frank dan Goyal (2003), Chen (2004), dan Cheng dan Shiu (2007), dimana profitabilitas akan memiliki pengaruh signifikan terhadap rasio utang. Dan juga mengacu pada pendapat Myers (2001), struktur modal dari entitas-entitas bisnis yang ada cenderung mengikuti model dari teori trade off, dimana semakin tinggi profitabilitas, maka rasio utang juga akan meningkat.

Model trade off juga akan didukung dengan ukuran entitas yang mengikuti rasio utang, dimana hasil penelitian ini mendukung hasil-hasil penelitian dari Rajan dan Zingales (1995), Graham (1996), Berger, Ofek, dan Yermack (1997), Udomsirikul, Jumreornvong, dan Jiraporn (2011), Amore, Minichilli, dan Corbetta (2011), Hovakimian, Opler, dan Titman (2001), Booth, Aivazian, Kunt, dan Maksimovic (2001), Frank dan Goyal (2003), Cheng dan Shiu (2007), Elliott, Kant, dan Warr (2008). Selain itu, hasil pengujian atas waktu pasar (market timing) juga mendukung hasil-hasil penelitian dari Asquith dan Mullins (1986), Hovakimian, Hovakimian, dan Tehranian (2004), Cheng dan Shiu (2007), Cai dan Zhang (2011), Frank dan Goyal (2004) dan Kayhan dan Titman (2007), yang seolah-olah menunjukkan entitas-entitas bisnis akan mengikuti pola model pecking order.

Akan tetapi, apabila dilakukan kontrol atas variabel rasio utang dan variabel ukuran entitas, fenomena atas struktur modal untuk mengikuti model trade off hanya muncul pada tahun 2009, khususnya bagi entitas-entitas bisnis yang memiliki rasio utang yang tinggi. Sedangkan entitas-entitas bisnis yang memiliki rasio utang yang kecil, cenderung mengikuti waktu pasar (market timing), akan tetapi apabila mengontrol variabel ukuran, maka pola model trade off akan terjadi pada entitas-entitas bisnis dengan rasio utang yang kecil tetapi memiliki ukuran yang besar, sedangkan entitas-entitas bisnis dengan rasio utang dan ukuran entitas yang kecil akan cenderung mengikuti model pecking order. Dalam periode tahun 2010 sampai dengan 2012, efek waktu pasar semakin mendominasi dalam penentuan struktur modal entitas-entitas bisnis yang ada, walaupun model trade off masih dapat ditunjukkan dengan adanya signifikansi ukuran entitas bisnis, akan tetapi efek ini hanya terjadi pada entitas-entitas yang memiliki rasio utang yang rendah.

\section{Kesimpulan}

Secara umum, struktur modal dari entitas-entitas bisnis dalam periode tahun 2009-2012 mengikuti model trade off, dan waktu pasar (market timing) mempunyai pengaruh dalam memberikan efek pecking order. Akan tetapi, apabila dianalisis untuk setiap periode, maka struktur modal dari entitas-entitas bisnis akan didominasi oleh efek waktu pasar, khususnya bagi entitas-entitas bisnis yang memiliki rasio utang yang rendah.

\section{Daftar Pustaka}

Alti, A. (2006). How Persistent Is the Impact of Market Timing on Capital Structure? The Journal of Finance, 61(4), 1681-1710.

Amore, M. D., Minichilli, A., dan Corbetta, G. (2011). How Do Managerial Successions Shape Corporate Financial Policies in Family Firms? Journal of Corporate Finance, 17(4), 1016-1027.

Asquith, P., dan Mullins, D. W., Jr. (1986). Equity Issues and Offering Dilution. Journal of Financial Economics, 15(1-2), 61-89.

Baker, M., dan Wurgler, J. (2002). Market Timing and Capital Structure. The Journal of Finance, 57(1), 1-32.

Berger, P. G., Ofek, E., dan Yermack, D. L. (1997). Managerial Entrenchment and Capital Structure Decisions. The Journal of Finance, 52(4), 1411-1438.

Booth, L., Aivazian, V., Kunt, A. D., dan Maksimovic, V. (2001). Capital Structures in Developing Countries. The Journal of Finance, 56(1), 87-130. 
Brendea, G. (2012). Testing the Impact of Market Timing on the Romanian Firms' Capital Structure. Procedia Economics and Finance, 3, 138-143.

Cai, J., dan Zhang, Z. (2011). Leverage Change, Debt Overhang, and Stock Prices. Journal of Corporate Finance, 17(3), 391-402.

Chen, J. J. (2004). Determinants of Capital Structure of Chinese-Listed Companies. Journal of Business Research, 57(12), 1341-1351.

Cheng, S. R., dan Shiu, C. Y. (2007). Investor Protection and Capital Structure : International Evidence. Journal of Multinational Financial Management, 17(1), 30-44.

Clayton, M. J., dan Reisel, N. (2013). Value Creation from Asset Sales: New Evidence from Bond and Stock Markets. Journal of Corporate Finance, 22, 1-15.

Crutchley, C. E., Jensen, M. R.H., Jahera, J. S., Jr., dan Raymond, J. E. (1999). Agency Problems and the Simultaneity of Financial Decision Making-The Role of Institutional Ownership. International Review of Financial Analysis, 8(2), 177-197.

Elliott, W. B., Kant, J. K., dan Warr, R. S. (2008). Market Timing and the Debt-Equity Choice. Journal of Financial Intermediation, 17(2), 175-197.

Fama, E. F., dan French, K. R. (2002). Testing Trade-Off and Pecking Order Predictions about Dividends and Debt. The Review of Financial Studies, 15(1), 1-33.

Frank, M. Z., dan Goyal, V. K. (2003). Testing the Pecking Order Theory of Capital Structure. Journal of Financial Economics, 67(2), 217-248.

Frank, M. Z., dan Goyal, V. K. (2004). The Effect of Market Conditions on Capital Structure Adjustment. Finance Research Letters, 1(1), 47-55.

Graham, J. R. (1996). Debt and the Marginal Tax Rate. Journal of Financial Economics, 41(1), 41-73.

Hovakimian, A., Opler, T., dan Titman, S. (2001). The Debt-Equity Choice. The Journal of Financial and Quantitative Analysis, 36(1), 1-24.

Hovakimian, A., Hovakimian, G., dan Tehranian, H. (2004). Determinants of Target Capital Structure : The Case of Dual Debt and Equity Issues. Journal of Financial Economics, 71(3), 517-540.

Jensen, G. R., Solberg, D. P., dan Zorn, T. S. (1992). Simultaneous Determination of Insider Ownership, Debt, and Dividend Policies. Journal of Financial and Quantitative Analysis, 27(2), 247-263.

Kayhan, A., dan Titman, S. (2007). Firms' Histories and their Capital Structures. Journal of Financial Economics, 83(1), 1-32.

Myers, S. C. (2001). Capital Structure. The Journal of Economic Perspectives, 15(2), 81-102.

Rajan, R. G., dan Zingales, L. (1995). What Do We Know about Capital Structure? Some Evidence from International Data. The Journal of Finance, 50(5), 1421-1460.

Titman, S. dan Wessels, R. (1988). The Determinants of Capital Structure Choice. The Journal of Finance, 43(1), 1-19.

Udomsirikul, P., Jumreornvong, S., dan Jiraporn, P. (2011). Liquidity and Capital Structure : The Case of Thailand. Journal of Multinational Financial Management, 21(2), 106-117. 